\title{
IGF1 stimulates greater muscle hypertrophy in the absence of myostatin in male mice
}

\author{
Alexander Hennebry', Jenny Oldham', Tea Shavlakadze², Miranda D Grounds², \\ Philip Sheard3, Marta L Fiorotto4, Shelley Falconer', Heather K Smith', Carole Berry', \\ Ferenc Jeanplong', Jeremy Bracegirdle', Kenneth Matthews', Gina Nicholas', \\ Mônica Senna-Salerno', Trevor Watson'1 and Christopher D McMahon'1
}

${ }^{1}$ AgResearch Ltd, Hamilton, New Zealand

2School of Anatomy, Physiology \& Human Biology, The University of Western Australia, Crawley, Western Australia, Australia

3Department of Physiology, University of Otago, Dunedin, New Zealand

4 USDA/ARS Children's Nutrition Research Center, Baylor College of Medicine, Houston, Texas, USA

${ }^{5}$ Department of Exercise Sciences, University of Auckland, Auckland, New Zealand

Correspondence should be addressed to C McMahon

Email

mcmahonc@xtra.co.nz

\begin{abstract}
Insulin-like growth factors (IGFs) and myostatin have opposing roles in regulating the growth and size of skeletal muscle, with IGF1 stimulating, and myostatin inhibiting, growth. However, it remains unclear whether these proteins have mutually dependent, or independent, roles. To clarify this issue, we crossed myostatin null ( $\mathrm{Mstn}^{-/-}$) mice with mice overexpressing $/ g f 1$ in skeletal muscle $\left(I g f 1^{+}\right)$to generate six genotypes of male

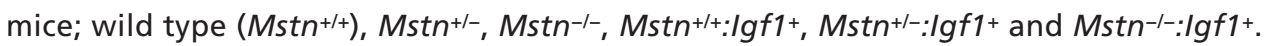
Overexpression of Igf1 increased the mass of mixed fibre type muscles (e.g. Quadriceps femoris) by $19 \%$ over Mstn+/+, 33\% over Mstn ${ }^{+/-}$and $49 \%$ over Mstn ${ }^{-/-}(P<0.001)$. By contrast, the mass of the gonadal fat pad was correspondingly reduced with the removal of Mstn and addition of Igf1. Myostatin regulated the number, while IGF1 regulated the size of myofibres, and the deletion of Mstn and Igf1+ independently increased the proportion of fast type IIB myosin heavy chain isoforms in $T$. anterior (up to $10 \%$ each, $P<0.001)$. The abundance of AKT and rpS6 was increased in muscles of

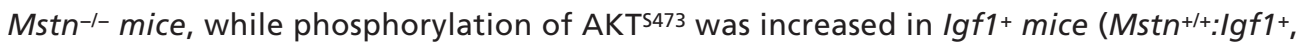

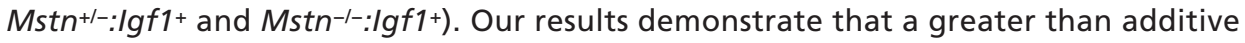
effect is observed on the growth of skeletal muscle and in the reduction of body fat when myostatin is absent and IGF1 is in excess. Finally, we show that myostatin and IGF1 regulate skeletal muscle size, myofibre type and gonadal fat through distinct mechanisms that involve increasing the total abundance and phosphorylation status of AKT and rpS6.
\end{abstract}

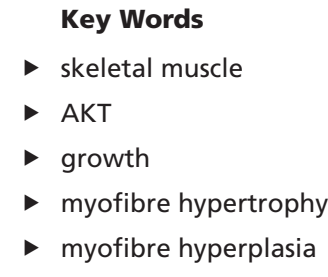

Journal of Endocrinology (2017) 234, 187-200

\section{Introduction}

Two factors play critical but opposing roles in regulating the growth and size of skeletal muscle. The growth hormone, insulin-like growth factor-1 (GH-IGF1) axis stimulates growth and accounts for $83 \%$ of postnatal growth and the increased muscle size (hypertrophy) in young mice (Lupu et al. 2001). Locally produced IGF1

Published by Bioscientifica Ltd 
is now considered to have the predominant influence on growth of tissues and organs as was convincingly demonstrated when liver-specific deletion of $I g f 1$ failed to inhibit growth of mice despite a $75 \%$ reduction in the concentration of IGF1 in blood (Sjogren et al. 1999, Yakar et al. 1999). Thus, local delivery of IGF1 to skeletal muscle is essential for growth (Shavlakadze et al. 2010). The benefits of $I g f 1$ overexpression on adult muscles in homeostasis and ageing muscles are debated: while two studies reported that viral or transgenic overexpression of Igf1 targeted to skeletal muscle reduced the extent of sarcopenia in mice aged up to 24 months (BartonDavis et al. 1998, Musaro et al. 2001), more recent studies using transgenic $I g f 1$ mice aged up to 28 months found that IGF1 alone did not prevent the loss of mass and strength of old muscles (McMahon et al. 2014). In contrast to IGF1, myostatin inhibits muscle growth. In the absence of myostatin, the mass of skeletal muscles is increased two- to three-fold more than that in wildtype mice during development (McPherron et al. 1997). Despite the importance of IGF1 and myostatin during growth, their precise molecular interactions in regulating the critical early events of postnatal growth are unclear.

Myostatin and IGF1 activate common and independent signal transduction pathways. It is well documented that myostatin binds and activates activin type $2 \mathrm{~B}$ receptors to promote phosphorylation of $S \mathrm{mad} 2 / 3$ (Rebbapragada et al. 2003), while IGF1 activates the IGF1 receptor and phosphorylates PI3 kinase (PI3K) and AKT (Rommel et al. 2001). The PI3K/AKT pathway is common to both factors, and there is considerable cross-regulation between the two, wherein myostatin inhibits AKT to block IGF1-induced hypertrophy of myotubes (Morissette et al. 2009), while IGF1 inhibits myostatin-induced activation of Smad3 (Retamales et al. 2015). Given that both factors are important regulators of muscle development, it remains unclear if both the absence of myostatin and excess IGF1 would increase the growth of skeletal muscle more than either condition alone. For example, the absence of myostatin during foetal development increases the number of myofibres, while the diameter of myofibres is increased in postnatal muscle (McPherron et al. 1997, Amthor et al. 2009). Furthermore, experimental antagonism to block the function of myostatin using antibodies (Latres et al. 2015), follistatin, which binds to and antagonises myostatin (Amthor et al. 2004), or antagonists of the activin2B receptor, also induces hypertrophy of myotubes in vitro and postnatal myofibres (Lee \& McPherron 2001). However, when myostatin activity is blocked, hypertrophy still requires the presence of IGF1 receptors (Kalista et al. 2012, Winbanks et al. 2012). Therefore, it appears that IGF1 is critical for enabling the actions of myostatin on muscle development.

Postnatal growth of skeletal muscles in mice is primarily due to hypertrophy, with increasing net protein content associated with elongation and expansion of the cross-sectional area of myofibres, because the number of myofibres is fixed before birth (Rowe \& Goldspink 1969, Ontell et al. 1984, Timson \& Dudenhoeffer 1990, White et al. 2010). Hypertrophy of myofibres occurs when the balance of protein synthesis and degradation is altered to increase protein accretion. Protein synthesis involves the PI3K/AKT/mTOR pathway, downstream of which is p70S6k, which regulates phosphorylation of 4EBP1 and rpS6 (Dever 2002, Proud 2004, Ruvinsky \& Meyuhas 2006, Laplante \& Sabatini 2012, Morita et al. 2015). To initiate protein synthesis, the repressor protein 4EBP1 becomes phosphorylated, which allows it to disengage from the translation initiation factor eIF4E on the $5^{\prime}$ cap-end of nascent mRNA to enable assembly of the eIF4F complex (Dever 2002, Proud 2004, Ruvinsky \& Meyuhas 2006, Laplante \& Sabatini 2012, Morita et al. 2015). In addition, phosphorylated rpS6 promotes translation of mRNAs that encode ribosomal proteins and other translation factors, which leads to an increased cellular capacity for protein synthesis (Proud 2004, Magnuson et al. 2012). Myostatin inhibits protein synthesis via inhibiting p70S6k and rpS6 (Trendelenburg et al. 2009, Welle et al. 2009), while IGF1 stimulates phosphorylation of 4EBP1 and rpS6 (Shen et al. 2005, Gao et al. 2015). Thus, the two factors, having opposing effects, could act in an additive or synergistic manner via common or distinct pathways to establish muscle mass.

To elucidate such potential actions, we investigated the role of IGF1 on the growth of skeletal muscle in the presence and absence of myostatin. Our aims were to determine (1) if increased IGF1 would increase the mass of skeletal muscles when the myostatin gene was removed, and (2) what effect increased IGF1 may have on myofibre number, size and type, on body composition and on downstream signalling targets.

\section{Materials and methods}

\section{Transgenic mice}

This research was approved by the Ruakura Animal Ethics Committee (Application 1161). Generation of Mstn-/-
(C) 2017 Society for Endocrinology Printed in Great Britain
Published by Bioscientifica Ltd 
mice (where all tissues lack expression of Mstn) has been previously described (McPherron et al. 1997). We obtained a breeding pair of these mice as a gift from S-J Lee (Johns Hopkins University School of Medicine, Baltimore, MD, USA). In Study 1, male wild-type mice that express myostatin $\left(\mathrm{Mstn}^{+/+}\right)$and $\mathrm{Mstn}^{-/-}$mice were used (see below). Study 2 used transgenic Igf1 (C2:Ea) mice generated at the European Molecular Biology Laboratory, Rome, Italy by N Winn and N Rosenthal: the MLC/Igf1 (C2:Ea) expression construct was generated by cloning the mouse $I g f 1$ (C2:Ea) cDNA sequences into the previously described skeletal muscle-specific expression cassette containing the myosin light chain (MLC) 1/3 promoter, a SV40 polyadenylation signal, followed by the MLC1/3 enhancer sequence (Rosenthal et al. 1989, Musaro et al. 2001, Shavlakadze et al. 2010). In these MLC/Igf1 transgenic mice, the IGF1 is most highly expressed in fast-twitch myofibres in the order 2B, 2X and 2A (Shavlakadze et al. 2005). The Igf1 (C2:Ea) (FVB background) and $\mathrm{Mstn}^{-1-}$ (C57BL/6J background) mice were maintained as separate colonies at the Ruakura campus of AgResearch Ltd. The F1 generation from a cross of Igf1 (C2:Ea) and $\mathrm{Mstn}^{-1-}$ founders was used to produce six genotypes in the F2 offspring: $\mathrm{Mstn}^{+/+}$(no Igf1 transgene), Mstn ${ }^{+-}, \mathrm{Mstn}^{-/-}, \mathrm{Mstn}^{+/+}: \mathrm{Igf1}^{+}, \mathrm{Mstn}^{+/-}: \mathrm{Igf1}^{+}$ and $\mathrm{Mstn}^{-/}: \mathrm{Igf1^{+ }}$ ) for Study 2. Only male mice were used for Study 2, and all mice, including $\mathrm{Mstn}^{+/+}$, had the same $\mathrm{FVB} \times \mathrm{C} 57 \mathrm{Bl} / 6 \mathrm{~J}$ background.

Mice were housed 2-4 per cage in a temperaturecontrolled $\left(21^{\circ} \mathrm{C}\right)$ and light-controlled $(12 \mathrm{~h}: 12 \mathrm{~h}$, light:darkness cycle) animal facility at Ruakura Research Centre. Mice had ad libitum access to a standard rodent chow (Specialty Feeds, Glen Forest, Western Australia; protein $19.4 \%$ (by weight), total fat $4.8 \%$, crude fibre $4.8 \%$ and digestible energy $14 \mathrm{MJ} \mathrm{ME} / \mathrm{kg}$ ) and water.

\section{Study 1. Quantification of Igf1Ea mRNA in muscles of $\mathrm{Mstn}^{+/+}$and $\mathrm{Mstn}^{-/-}$mice during postnatal growth from 4 to 20 weeks of age}

Male $\mathrm{Mstn}^{+/+}$and $\mathrm{Mstn}^{-/-}$pups were killed at 4, 8, 12 and 20 weeks ( $n=6$ mice per genotype, per age). Quadriceps muscles were extracted, and mRNA was prepared for quantitation of Igf1Ea via qPCR (see below).

\section{Study 2. Phenotype analyses for six genotypes during early postnatal growth (sampled at 12 weeks of age)}

Male pups with or without the $I g f 1$ (C2:Ea) transgene that had a matching myostatin genotype $\left(\mathrm{Mstn}^{+/+}, \mathrm{Mstn}^{+/-}\right.$or
$M_{s t n^{-/}}$) within litters were included in the study. Mice were weighed weekly, and grip strength was measured before mice were killed at 12 weeks of age, and many tissues were sampled for molecular analyses as outlined below ( $n=8$ per genotype). Mice were not fasted before death and were killed using $\mathrm{CO}_{2}$ asphyxiation followed by cervical dislocation. At death, a sample of blood was collected via cardiac puncture into a tube containing EDTA. Plasma was harvested and stored at $-20^{\circ} \mathrm{C}$ before assay of IGF1.

\section{Grip strength (Study 2 only)}

The grip strength of each mouse was assessed 2 days before death using the Muromachi grip strength metre (model MK-380M, Muromachi Kikai Co., Tokyo, Japan). This metre has a mesh pad on which a mouse is placed and can grip with all paws. Each mouse was placed on the mesh pad (attached to a force transducer) and pulled backwards by the base of the tail until release, for 5 consecutive attempts. The highest and lowest scores were removed, and the grip strength value for each mouse was recorded as the mean of the 3 remaining scores. The mean grip strength was then expressed relative to body mass (Force $(\mathrm{kg}) / \mathrm{BW}(\mathrm{kg})$ ).

\section{Muscle and fat pad collection (Study 2 only)}

Following euthanasia, the Quadriceps femoris (quadriceps), B. femoris, gastrocnemius, plantaris, soleus, Extensor digitorum longus (EDL) and Tibialis anterior (T. anterior) muscles were excised from both hind limbs, along with the heart and weighed. The soleus is a slow-twitch muscle. The T. anterior, plantaris and $E D L$ are fast-twitch muscles, and the quadriceps, B. femoris and gastrocnemius muscles have a mixed myofibre composition (Hamalainen \& Pette 1993, Augusto et al. 2004). Because mouse muscles are small, we had to use multiple muscles for the analyses. For Study 1 , we used the quadriceps for qPCR and for Study 2, we used the $T$. anterior for muscle fibre typing, the gastrocnemius for qPCR and Western analyses and the quadriceps for measuring the amount of IGF1 in skeletal muscle.

The length of the tibia was measured and used to normalise the mean masses of skeletal muscles and the heart as previously described (White et al. 2016). The gonadal fat pads were excised and weighed and were expressed as a per cent of body mass. The gonadal fat pads correlate highly with total body fat (Rogers \& Webb 1980).

Published by Bioscientifica Ltd. 


\section{Morphometric analysis and histology (Study 2 only)}

The $T$. anterior muscles were cut transversely in the midbelly region, mounted in OCT compound and frozen in isopentane cooled in liquid nitrogen. Cryosections $(8 \mu \mathrm{m})$ were collected onto glass slides and immunostained with a rabbit anti-laminin antibody (L9393, Sigma) (dilution 1:300). A digital image of the entire transverse muscle section was produced by tiling non-overlapping individual images acquired using a Nikon Eclipse Ti microscope and a CoolSNAP EZ digital camera. The resolution allowed the total number of myofibres to be counted from 3 to 5 mice per genotype. The minimal myofibre diameter was calculated from automated digital capture of an average of 2900 myofibres per T. anterior muscle using FoveaPro software (Reindeer Graphics, Inc.) for 5-8 mice per genotype. This method has the advantage of being semiautomated and captures a large number of myofibres for analysis. The method also copes with myofibres oriented obliquely by treating each myofibre as a cylinder, wherein the minimal diameter is the least affected parameter (Briguet et al. 2004). The myofibre diameters were binned into $5 \mu \mathrm{m}$ intervals from 10 to $100 \mu \mathrm{m}$ using the Frequency function in Microsoft Excel to produce a frequency distribution for each group.

\section{RNA extraction and quantitative (q) PCR (Studies 1 and 2)}

Total RNA was extracted from the quadriceps muscle (Study 1) and from the gastrocnemius muscles (Study 2) using Trizol reagent (Invitrogen), and complementary DNA (cDNA) was reverse transcribed (RT) from $2 \mu$ g total RNA using qSCRIPT (Quanta BioSciences, Maryland, USA) as described previously (Smith et al. 2014). The qPCR was carried out using a Lightcycler 2.0 (Roche Diagnostics) and Roche Faststart DNA master PLUS SYBR Green I mix (Roche Diagnostics). The primers for $P g c 1 A, P g c 1 B, M e f 2 c$, $I g f 1 \mathrm{Ea}, I g f 1$ transgene, $I g f 1$ receptor and binding proteins and myostatin are presented in Table 1 . Standard curves were established by serial dilution of a pool of cDNA obtained from each sample, and results were normalised to the concentration of ssDNA in the RT samples (Lundby et al. 2005).

\section{Western blot analyses (Study 2 only)}

Protein was extracted from the gastrocnemius muscle, and Western blotting was performed as previously described (Smith et al. 2014). Membranes were incubated with rabbit anti-AKT1/2/3 (1:10,000, \#8312, Santa Cruz Biotechnology), rabbit anti-phospho AKT ${ }^{543}$ (1:500, \#7985, Santa Cruz Biotechnology), rabbit anti-4EBP1 (1:500, \#R113, Santa Cruz Biotechnology), rabbit anti-phospho-4EBP1 (1:2000, Thr37/46, \#236B4, Cell Signaling Technology), rabbit anti-rpS6 (1:1000, \#2217, 5G10, Cell Signaling Technology) and rabbit antiphospho-rpS6 (1:1000, Ser235/236, \#2211, Cell Signaling Technology), and the abundance of each protein was detected with enhanced chemiluminescence. GAPDH was used as a loading control (mouse anti-rabbit GAPDH (1:10,000, \#RDI-TRK5G4-6C5, Research Diagnostics, Inc., NJ, USA). The optical densities of each immunoreactive band were captured with a densitometer (GS 800, Bio-Rad Laboratories (NZ) Pty Ltd) and analysed using Quantity One software (Bio-Rad Laboratories (NZ) Pty Ltd).

\section{Assessment of myosin heavy chain (MyHC) isoforms (Study 2 only)}

Changes in the composition of MyHC in T. anterior muscles were determined electrophoretically as described previously (Smith et al. 2014). Despite improvements in separation of the bands using an $8 \mathrm{M}$ urea/2 $\mathrm{M}$ thiourea buffer in which the samples were loaded, the $2 \mathrm{~A}$ and $\mathrm{X}$ bands typically do not separate as cleanly in mouse skeletal muscle as they do in rat skeletal muscle (Blough et al. 1996). A 50:50 mixture of mouse soleus and EDL muscle were run in the gels to act as a marker to help identify MyHC bands.

\section{IGF1 assay (Study 2 only)}

Concentrations of IGF1 protein were assayed in homogenates from quadriceps muscles and in plasma using a mouse/rat IGF1 ELISA kit (\#MG100, Quantikine ELISA, R\&D Systems).

\section{Statistical analysis}

All data were analysed with GenStat v17 using the general procedure of ANOVA with variations in myostatin copy number $\left(\mathrm{Mstn}^{+/+}, \mathrm{Mstn}^{+-}\right.$, or Mstn-l-) and IGF1 (Igf1, or $\left.I g f^{+}\right)$as main effects along with their interaction. Post hoc multiple comparisons were performed using Tukey's method (GenStat 2003). Data are presented as means along with the standard error of the mean (s.E.m.), or standard error of the differences between means (s.E.D.).

Published by Bioscientifica Ltd. 
Table 1 Primers used for qPCR (Study 1 and 2).

\begin{tabular}{ll}
\hline Gene & Primer sequences \\
\hline Pgc1A & Fwd: GCAGAGACAAATGTGCTTCG \\
& Rev: GGAGGAGTTGTGGGAGGAGT \\
Pgc1B & Fwd: CCAGACCAGCCTCAGTTCCAGA \\
& Rev: TTGGGGAGCAGGCTTTCACTC \\
Ief2c & Fwd: GTGTTGCTCAAGTACACCGAG \\
& Fev: CTGGACACTGGGATGGTAACT \\
Igf1Ea & Rev: AAATGTACTTCCTTCTGGGTCT \\
& Fwd: ACTGACATGCCCAAGACTCAG \\
Igf1(C2:Ea)a & Rev: ATTCCACCACTGCTCCCATTC \\
& Fwd: CTGCGGCGATGAAGAGAAGAAAA \\
Igf1r & Rev: TACCGGTGCCACGTTATGATGATT \\
& Fwd: AATGGCCGCGGGTTCTGC \\
IgfBP3 & Rev: TTCTGGGTGTCTGTGCTTTGAG \\
& Fwd: CCATCCAGGAAAGCCTGCAG \\
IgfBP4 & Rev: TGGAAGTTGCCGTTGGGTCACAG \\
IgfBP5 & Rev: ACAAACTTGGACTGGGTCAGC \\
& Fwd: CCCCGAGAGAACGAAG \\
IgfBP6 & Rev: CACAGTTTGGCACATAGAG \\
& Fwd: ACCCATGAAAGACGGTACAAG \\
Mstn & Rev: TCATCACAGTCAAGCCCAAAG \\
&
\end{tabular}

\begin{tabular}{ccc}
\hline Size $(\mathrm{bp})$ & & Annealing $\left({ }^{\circ} \mathrm{C}\right)$ \\
\hline 269 & 60 \\
164 & 60 \\
260 & 60 \\
301 & 60 \\
283 & 60 \\
546 & 60 \\
269 & 60 \\
298 & 60 \\
200 & 60 \\
307 & 60 \\
288 & \\
\hline
\end{tabular}

\begin{tabular}{l}
\hline GenBank accession \\
XM_006503779.3 \\
NM_133249.2 \\
NM_001170537.1 \\
NM_001111275.2 \\
Shavlakadze et al. (2010) \\
NM_010513.2 \\
NM_008343.2 \\
NM_010517.3 \\
NM_010518.2 \\
NM_008344.3 \\
NM_010834.3
\end{tabular}

aFwd primer is common to exon 4, while the reverse primer is for the SV40 enhancer for the transgene.

\section{Results}

\section{Study 1}

There was significantly less Igf1Ea mRNA (the principal endogenous $I g f 1$ transcript) in quadriceps muscles of Mstn $^{-/-}$mice at $4(P<0.01)$ and $8(P<0.01)$ weeks (about half the amount) compared with $\mathrm{Mstn}^{+/+}$mice, with concentrations of $I g f 1 E a$ mRNA reducing after this age in both strains (as muscle growth slows down) to similar concentrations by 20 weeks of postnatal growth (Fig. 1).

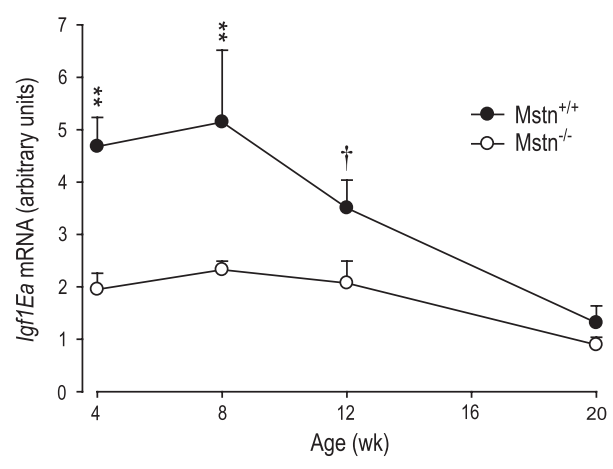

\section{Figure 1}

Concentrations of mRNA in muscles of wild-type $\left(\mathrm{Mstn}^{+/+}\right)$and myostatin null (Mstn-l-) mice (Study 1). Arbitrary concentrations of endogenous Igf1Ea mRNA in quadriceps muscles of $\mathrm{Mstn}^{+/+}$and $\mathrm{Mstn}^{-/-}$mice from 4 to 20 weeks (Study $1, n=6$ per genotype). Asterisks and symbols indicate significant differences between the strains at each age $(* * P<0.01 ;+P<0.1)$.
Therefore, we anticipated that skeletal muscles would grow to a greater size in Mstn-/- mice if the concentration of Igf1Ea IGF1 was increased locally, using transgenic Igf1 (C2:Ea) mice (Study 2).

\section{Study 2}

To confirm that the $I g f 1$ transgene was being expressed in muscles of the Mstn+/+:Igf1+ Mstn $^{+/-}: I_{\delta} f 1^{+}$and Mstn $^{-/-}: I g f 1^{+}$ mice, we quantified Igf1 mRNA in the gastrocnemius muscles and observed that it was 20-fold higher $(P<0.001)$ than in the Mstn+/+, Mstn ${ }^{+/-}$and Mstn ${ }^{-/-}$muscles (Fig. 2A). In contrast, there was a main effect of overexpression of Igf1 which tended $(P=0.07)$ to decrease concentrations of myostatin mRNA in the gastrocnemius muscles of mice transgenic for Igf1 (there was no mRNA for the exon 3 coding region of myostatin in Mstn-1- mice) (Fig. 2B).

Sequential removal of myostatin together with overexpression of $I g f 1$ had a greater than additive effect on the rate of weight gain (Mstn $\times$ IGF1 interaction, $P<0.001)$, than the effect of each gene alone. Rates of weight gain over the 12 weeks were least in $\mathrm{Mstn}^{+/+}$mice and strikingly highest in $\mathrm{Mstn}^{-l^{-}} \mathrm{Igf1^{+ }}$ mice (Fig. 3A and B). The increase in body mass could be attributed to the corresponding greater growth of skeletal muscles (Fig. 3C and $\mathrm{E}$ ). There was no difference among genotypes in body length (nose to anus) or tibia length (Table 2) and so there was no contribution to the differences in mass due

Published by Bioscientifica Ltd. 
A

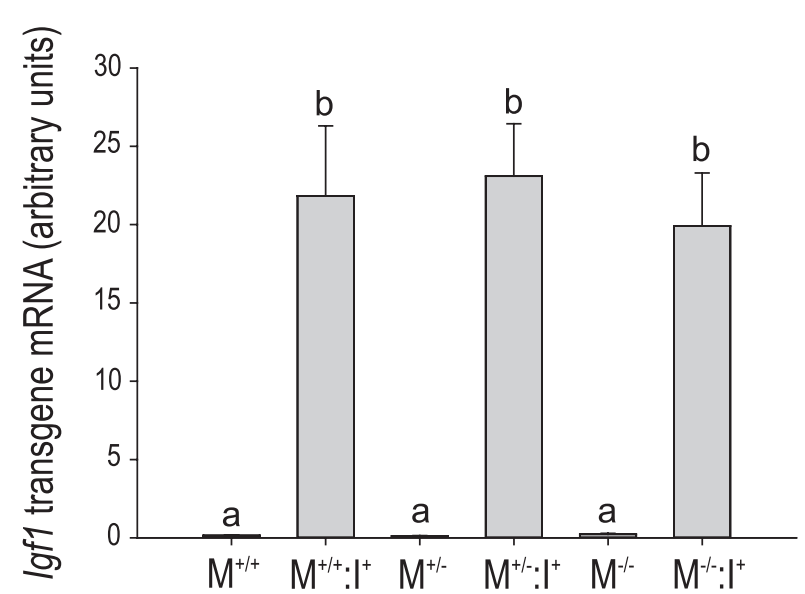

B

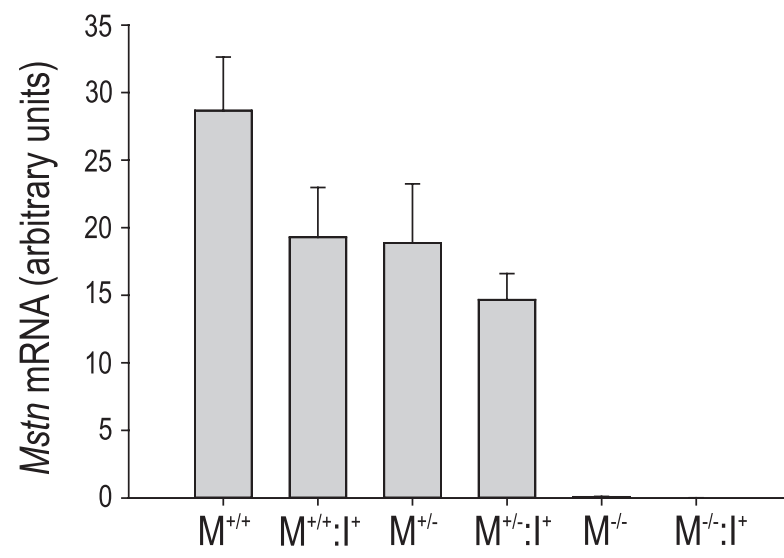

Figure 2

Concentrations of mRNA in muscles of wild-type and transgenic mice (Study 2). (A) Arbitrary concentrations of the Igf1 transgene in the gastrocnemius muscles of Mstn ${ }^{+/+}\left(\mathrm{M}^{+/+}\right), \mathrm{Mstn}^{+/-}\left(\mathrm{M}^{+/-}\right), \mathrm{Mstn}^{-/-}\left(\mathrm{M}^{-/-}\right)$,

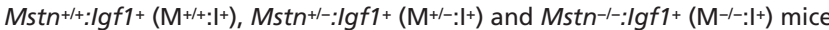
( $n=8$ per genotype). Unlike letters denote significance $(a, b P<0.001)$. (B) Arbitrary concentrations of Mstn mRNA in gastrocnemius muscles of the six genotypes of mice. Concentrations of myostatin mRNA were reduced $(P<0.001)$ with elimination of copy number and tended $(P=0.07$, main effect) to be reduced in muscles of Igf1Ea transgenic mice.

to allometric organ growth (other than that of skeletal muscle). The mass of the gonadal fat pad (corrected to body mass) was correspondingly reduced (Fig. 3D), and the mass of the heart (corrected to tibia length) was not affected by the genotypes (Fig. 3F). The combined action of these two genes on skeletal muscle growth was synergistic. Notably, the sizes of quadriceps (Fig. 3C) as well as the gastrocnemius, B. femoris, T. anterior, EDL and Plantaris muscles at 12 weeks of age (corrected to tibia length) were increased by up to 2-fold in $\mathrm{Mstn}^{-1-}$ mice, and there was a $\sim 20-30 \%$ increase in the mass of those muscles in all mice expressing the Igf1 transgene alone (Table 2). However, when combined $\left(\mathrm{Mstn}^{-/-}: \mathrm{Ig}^{\mathrm{S}} \mathrm{1}^{+}\right)$, there was nearly a 3-fold increase across fast-twitch muscles (Table 2).
The mass of the soleus, which is predominantly slow twitch (Augusto et al. 2004), was also increased, although to a lesser degree (less than two-fold increase) than muscles expressing the fast $2 \mathrm{X}$ and $2 \mathrm{~B}$ MyHCs (Table 2). In contrast, deletion of the myostatin gene biased the composition of myofibres of one of these muscles, the T. anterior, towards type 2B MyHC (6\% more for $\mathrm{Mstn}^{+/-}$ and $10 \%$ more for $\mathrm{Mstn}^{-/-}, P<0.001$, Fig. $4 \mathrm{~A}$ and B). Igf1 overexpression also increased the bias of myofibre type composition towards $2 \mathrm{~B}$ MyHC by $7 \%(P<0.001$, Fig. $4 \mathrm{~A}$ and $\mathrm{B})$. By contrast, the abundance of type $2 \mathrm{~A}$ and $\mathrm{X}$ (these bands did not separate during electrophoresis) were reduced from $27.9 \pm 0.6 \%$ in $\mathrm{Mstn}^{+/+}$controls by $20 \%$ in $\mathrm{Mstn}^{+/-}$and $36 \%$ in $\mathrm{Mstn}^{-/-}(P<0.001)$. In addition, Igf1 overexpression also decreased the abundance by $26 \%(P<0.001)$. Type $1 \mathrm{MyHC}$ was not discernible in the T. anterior.

To ascertain whether the increase in muscle growth was due to increased numbers of myofibres during development (myofibre hyperplasia) and/or hypertrophy, we counted and measured the minimal diameter of each myofibre within transverse sections collected from the middle of the $T$. anterior muscle. Removal of myostatin alone (Mstn-/-, Mstn-l-:Igf1+) increased the number of myofibres $(P<0.001$, Fig. $4 \mathrm{C})$ with no effect on myofibre diameter (Fig. 4D), while addition of $I g f 1$ alone $\left(\mathrm{Mstn}^{+/+}: \mathrm{Igf1}^{+}, \mathrm{Mstn}^{+--}: \mathrm{Igf1}^{+}, \mathrm{Mstn}^{-/-}: \mathrm{Igf1}^{+}\right)$increased their diameter, but not myofibre number $(P<0.001$, main effect) (Fig. 4C and D). The distribution of the diameters of myofibres was unimodal and showed a shift to the right with sequential removal of myostatin and addition of $I g f 1$ (Fig. 4E). Despite the increase in muscle size, the function, as assessed by grip strength, although greater overall (Fig. 4F), was not altered when normalised to body mass (Fig. 4G).

We measured concentrations of IGF1 protein in quadriceps muscles and blood to determine if IGF1 was getting into circulation to affect other tissues. Concentrations were increased $(\sim 40$ fold, $P<0.001)$ in quadriceps muscles of $I g f 1$ transgenic mice (Fig. 5A). However, there was no change in circulating concentrations of IGF1 (Fig. 5B). To determine if the lack of change in circulating concentrations of IGF1 was due to changes in expression of the IGF1 receptor, or of binding proteins, we measured the mRNA expression of Igf1r and Igfbp3-6. There was a main effect of the Igf1 transgene to reduce concentrations of Igf1r mRNA $(P<0.001)$, Igfbp 3 mRNA $(P<0.05)$, Igfbp4 mRNA $(P<0.1)$ and Igfbp6 mRNA $(P<0.05)$ in gastrocnemius muscles (Fig. 5C, D, E and F). By contrast,

Published by Bioscientifica Ltd 
A

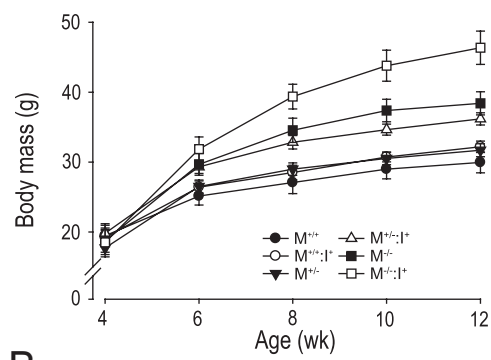

B
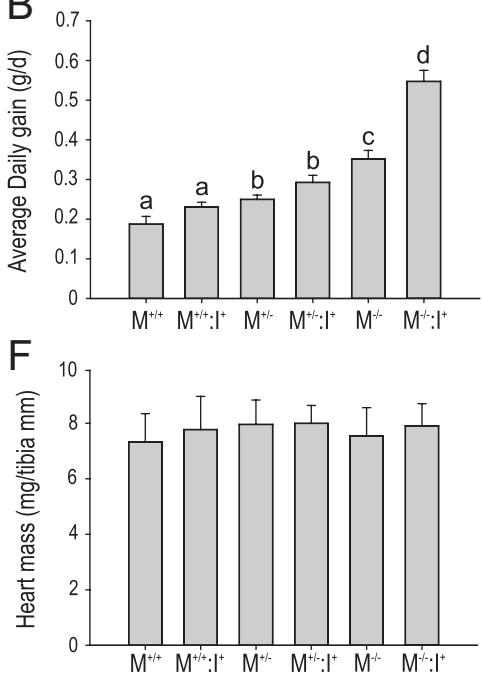

C
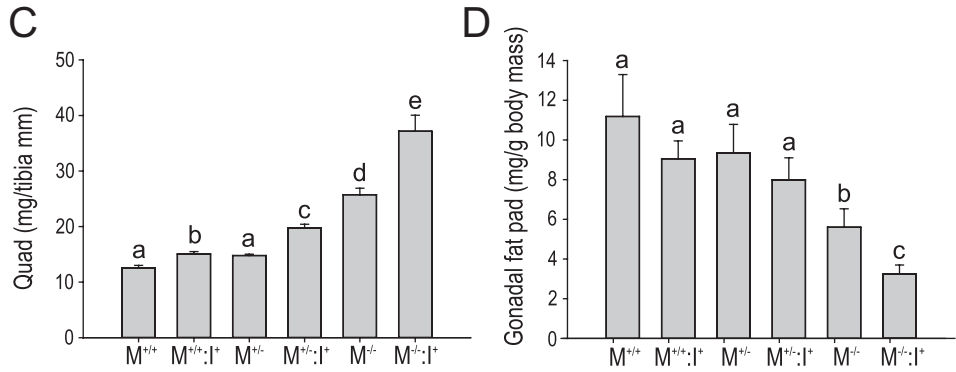

E

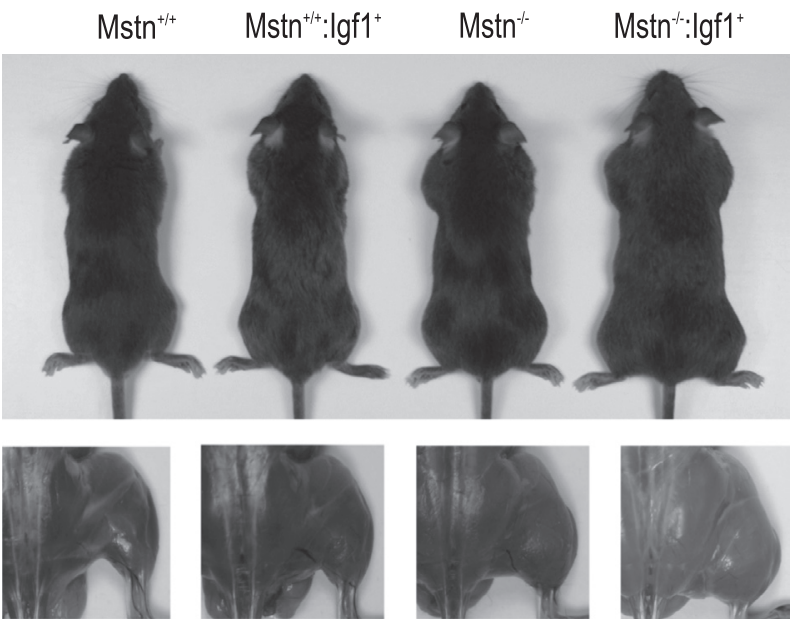

Figure 3

Body mass, muscle mass and growth dynamics of wild-type and transgenic mice (Study 2). (A) Body mass (mean \pm S.E.M.) of Mstn ${ }^{+/+}\left(\mathrm{M}^{+/+}\right), \mathrm{Mstn}^{+/-}\left(\mathrm{M}^{+/-}\right)$,

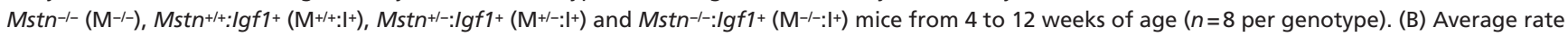
of daily growth of mice from 4 to 12 weeks of age. (C) Mass of the quadriceps muscle (mean \pm s.E.M.) normalised to tibia length and (D) mass of the gonadal fat pad (mean \pm s.E.M.) normalised to body mass at 12 weeks of age. (E) Four of the six genotypes of mice at death (top) and with skin removed (bottom) to show the extensive hypertrophy of the hind limb muscles. (F) Mass of the heart (mean \pm S.E.M., normalised to tibia length) for the six mouse genotypes. Unlike letters denote significance (at least $P<0.05$ ).

concentrations of Igfbp5 mRNA were increased $(P<0.001$ in gastrocnemius muscles in the absence of myostatin (Fig. 5G).
Total AKT was increased 2.5-fold in the absence of myostatin alone (Figs 6 and 7A, $P<0.001$, main effect), while IGF1 alone increased the abundance of pAKT ${ }^{5473}$

Table 2 Mass $(\mathrm{mg})$ of 6 different muscles corrected to length of tibia $(\mathrm{mm})$ for the 6 genotypes of mice that differed in (systemic) deletion of Mstn and/or addition of the Igf1 transgene expressed specifically in skeletal muscle throughout development (sampled at 12 weeks - Study 2).

\begin{tabular}{|c|c|c|c|c|c|c|c|c|c|c|}
\hline & \multirow[b]{2}{*}{ Mstn+l+ } & \multirow[b]{2}{*}{ Igf1+ } & \multirow[b]{2}{*}{ Mstn ${ }^{+/-}$} & \multirow[b]{2}{*}{ Mstn+l:Igf1+ } & \multirow[b]{2}{*}{ Mstn ${ }^{-1-}$} & \multirow[b]{2}{*}{ Mstn-1-:Igf1+ } & \multirow[b]{2}{*}{$n$} & \multicolumn{3}{|c|}{$\boldsymbol{P}$} \\
\hline & & & & & & & & Mstn & Igf1 & Mstn $\times \operatorname{lgf} 1$ \\
\hline Gast & $7.2 \pm 0.2^{a}$ & $8.9 \pm 0.3^{b}$ & $8.5 \pm 0.1^{b}$ & $10.6 \pm 0.3^{c}$ & $14.3 \pm 0.5^{d}$ & $20.7 \pm 0.8^{e}$ & 8 & 0.001 & 0.001 & 0.001 \\
\hline B. fem & $9.6 \pm 0.6^{a}$ & $11.7 \pm 0.4^{a}$ & $10.9 \pm 0.2^{a}$ & $14.9 \pm 0.6^{b}$ & $17.4 \pm 1.0^{c}$ & $28.2 \pm 1.5^{d}$ & 8 & 0.001 & 0.001 & 0.001 \\
\hline T. ant & $2.8 \pm 0.1^{a}$ & $3.5 \pm 0.1^{b}$ & $3.2 \pm 0.1^{a}$ & $4.5 \pm 0.2^{c}$ & $4.9 \pm 0.3^{c}$ & $7.6 \pm 0.4^{d}$ & 8 & 0.001 & 0.001 & 0.001 \\
\hline EDL & $0.64 \pm 0.13^{a}$ & $0.83 \pm 0.14^{a}$ & $0.66 \pm 0.02^{a}$ & $0.89 \pm 0.04^{b}$ & $1.08 \pm 0.06^{b}$ & $1.75 \pm 0.05^{c}$ & 8 & 0.001 & 0.001 & 0.01 \\
\hline Soleus & $0.38 \pm 0.02^{a}$ & $0.42 \pm 0.03^{a}$ & $0.41 \pm 0.02^{a}$ & $0.49 \pm 0.03^{b}$ & $0.59 \pm 0.03^{c}$ & $0.68 \pm 0.06^{d}$ & 8 & 0.01 & 0.001 & 0.637 \\
\hline Plantaris & $0.94 \pm 0.04^{a}$ & $1.17 \pm 0.02^{b}$ & $1.11 \pm 0.03^{a}$ & $1.53 \pm 0.07^{b}$ & $2.19 \pm 0.08^{c}$ & $3.09 \pm 0.17^{d}$ & 8 & 0.001 & 0.001 & 0.001 \\
\hline Tibia (mm) & $18.5 \pm 0.2$ & $18.1 \pm 0.1$ & $18.3 \pm 0.3$ & $18.4 \pm 0.2$ & $18.3 \pm 0.2$ & $18.2 \pm 0.2$ & 8 & 0.98 & 0.49 & 0.55 \\
\hline
\end{tabular}

The probability $(P)$ is given for the main effects of myostatin (Mstn) and (IGF1) genotypes and their interaction on muscles mass.

Unlike letters denote significant differences within rows (at least $P<0.05$ ).

B. fem, B. femoris; EDL, extensor digitorum longus; Gast, gastrocnemius; T. ant, T. anterior.

$\begin{array}{lr}\text { http://joe.endocrinology-journals.org } & \text { C } 2017 \text { Society for Endocrinology } \\ \text { DOI: } 10.1530 / \text { OE-17-0032 } & \text { Printed in Great Britain }\end{array}$


A

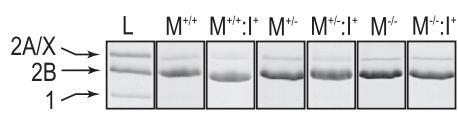

B
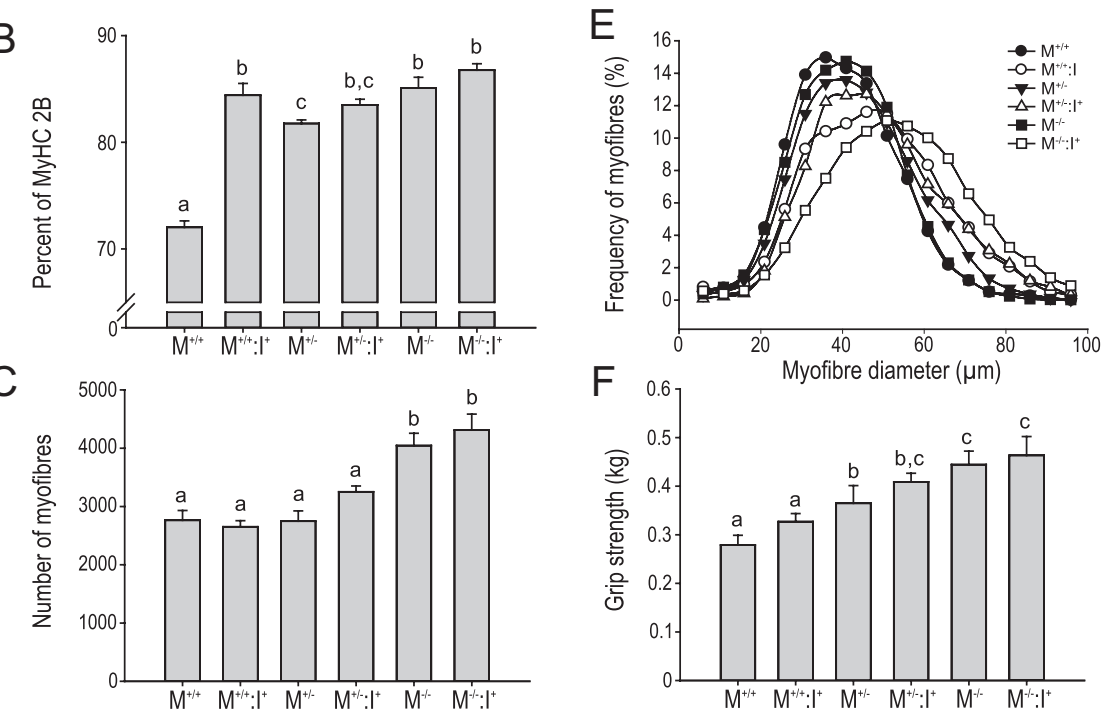

\section{Figure 4}

Myofibre phenotype of wild-type and transgenic mice (sampled at 12 weeks - Study 2).

(A) A representative image of an SDS-PAGE gel showing the separation of myosin heavy chains (MyHC) in T. anterior muscles along with a control sample (ladder, L) from a 50:50 mixture of soleus and EDL muscles from mice for use as a reference. (B) Percent of MyHC 2B (mean \pm S.E.M.) from the optical densities (ODs) in T. anterior muscles of Mstn $^{+/+}\left(\mathrm{M}^{+/+}\right)$, Mstn $^{+/-}\left(\mathrm{M}^{+/-}\right)$, Mstn $^{-/-}\left(\mathrm{M}^{-/-}\right)$, Mstn $^{+++}: I g f 1^{+}\left(\mathrm{M}^{+++}: I^{+}\right), \mathrm{Mstn}^{+/-}: \mathrm{lgf1} 1^{+}\left(\mathrm{M}^{++--}: \mathrm{I}^{+}\right)$and Mstn $^{-1-: I g f 1^{+}}\left(\mathrm{M}^{\left.-1-: I^{+}\right)}\right.$mice ( $n=8$ per genotype) (C) Number and (D) minimal diameter of myofibres (mean \pm S.E.M.) in the $T$. anterior muscles of the six genotypes of mice. (E) Frequency distribution of the minimal diameter of myofibres (10 $\mu \mathrm{m}$ bins) in $T$. anterior muscles of the six genotypes of mice. (F) Uncorrected grip strength (mean \pm S.E.M.) and (G) grip strength normalised to body mass of the six genotypes of mice. Unlike letters denote significance (at least $P<0.05$ ).

by 1.7-fold overall (Figs 6 and 7B, $P=0.002$, main effect). The ratio of phosphorylated to total AKT was reduced by $50 \%$ in the absence of myostatin $(P<0.05$, Fig. 7C). Total rpS6 was increased in the absence of myostatin alone by 1.4 -fold $(P<0.05$, Figs 6 and 7D), while there was no effect of either myostatin or IGF1 on phosphorylated rpS6 (Figs 6 and 7E) or the ratio of phosphorylated to total rpS6 (Figs 6 and 7F), or on total, phosphorylated or the ratio of phosphorylated to total 4EBP1 (Figs 6 and 7G, H and I).

To understand how the change in composition of myofibres was being regulated, we measured the mRNA expression of $M e f 2 c, P g c 1 A$ and $P g c 1 B$. There was a main effect of $I g f 1^{+}$to reduce expression of Mef2c mRNA (9.54 vs $12.43 \pm 1.45$ s.e.D., pooled means, $P<0.05)$ and $P g c 1 A$ (9.13 vs $13.41 \pm 1.50$ s.E.D., pooled means, $P<0.01$ ) in gastrocnemius muscles of mice transgenic for $I g f 1$ $\left(\mathrm{Mstn}^{+/+}: I g f 1^{+}, \mathrm{Mstn}^{+/-}: \mathrm{Igf1} 1^{+}\right.$and $\left.\mathrm{Mstn}^{+/-}: \mathrm{Igf1}^{+}\right)$compared with non-Igf1 transgenic mice $\left(\mathrm{Mstn}^{+/+}, \mathrm{Mstn}^{+/-}\right.$and Mstn $\left.^{-/-}\right)$. Similarly, there was a tendency $(P=0.06$, main effect) for concentrations of $P g c 1 B$ mRNA to be reduced in gastrocnemius muscles of mice transgenic for $I g f 1$
(10.5 vs $13.9 \pm 1.8$ s.E.D., pooled means) compared to nonIgf1 transgenic mice.

\section{Discussion}

These data are unique in showing for the first time that growth of skeletal muscle is modulated by the combined actions of IGF1 and myostatin with each factor having a distinct role - myostatin regulates hyperplasia and IGF1 regulates hypertrophy of myofibres. It is likely that these two processes are temporally separated because the number of myofibres is largely fixed before birth (Rowe \& Goldspink 1969, Timson \& Dudenhoeffer 1990), although myogenesis can continue in the $T$. anterior and $E D L$ muscles for up to a week postnatally (Li et al. 2015). Therefore, the absence of myostatin throughout in utero development is likely to have increased the number of myofibres prenatally. By contrast, hypertrophy of myofibres, an expansion of myofibre length and cross-sectional area, occurs progressively postnatally concomitant with an increase in the number of myonuclei 

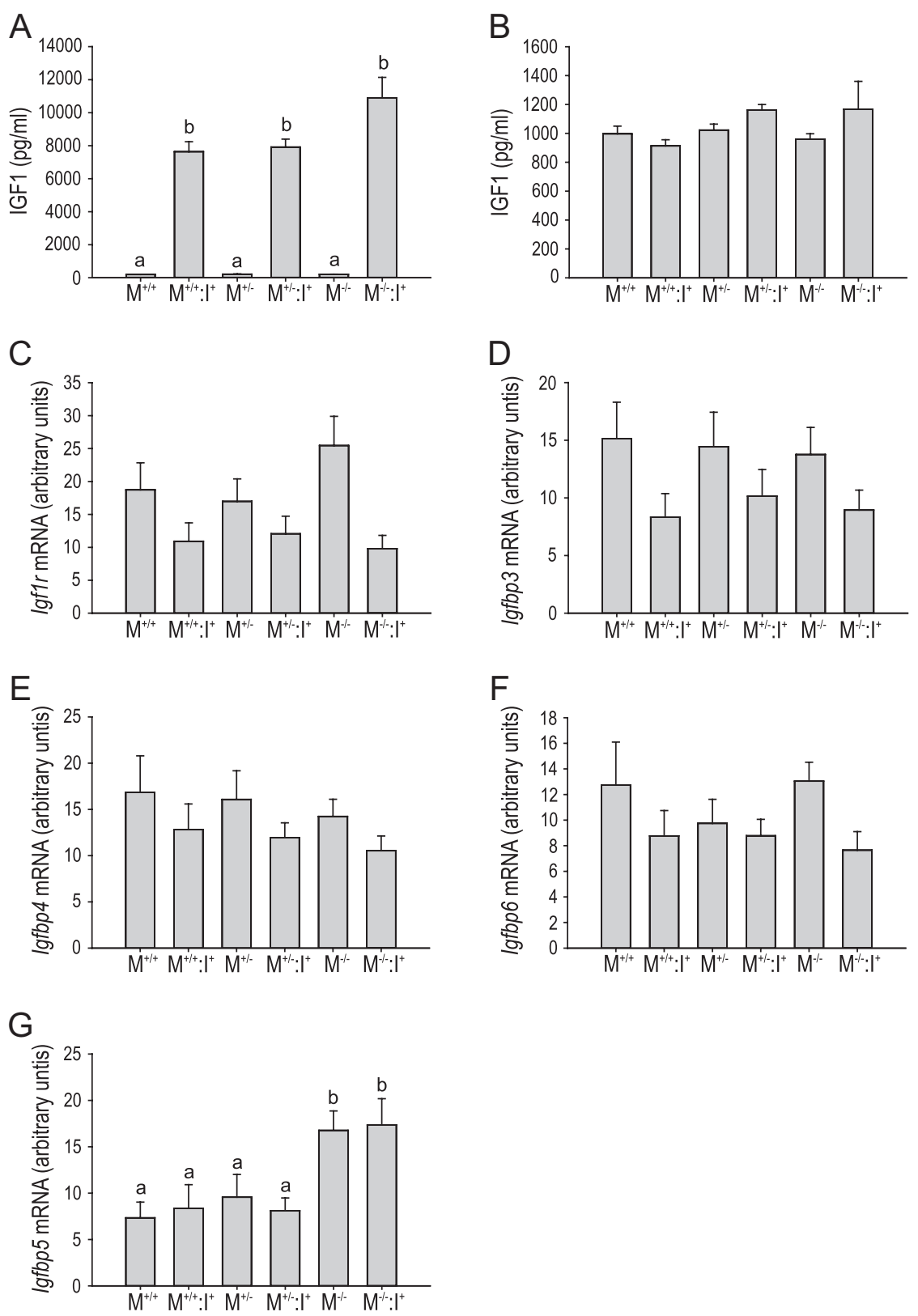

\begin{abstract}
Figure 5
Concentrations of IGF1 protein and expression of Igf1Ea, receptor and binding protein mRNA in wild-type and transgenic mice (sampled at 12 weeks - Study 2). (A) Concentrations of IGF1 protein in quadriceps muscles of $\mathrm{Mstn}^{+/+}\left(\mathrm{M}^{+/+}\right)$, Mstn $^{+/-}\left(\mathrm{M}^{+/-}\right)$, Mstn $^{-/-}\left(\mathrm{M}^{-/-}\right)$, Mstn $^{+++}:$Igf1 $1^{+}\left(\mathrm{M}^{+/+}: I^{+}\right)$,

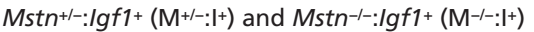
mice ( $n=8$ per genotype). (B) Concentrations of IGF1 protein in plasma of the same six genotypes of mice. (C) Arbitrary concentrations of Igf1 receptor ( $r$ ) mRNA, (D) IgfBP3 mRNA, (E) IgfBP4 mRNA, (F) IgfBP6 mRNA and (G) IgfBP5 mRNA in the gastrocnemius muscles of the six genotypes of mice. There was a main effect of the Igf1Ea transgene to reduce concentrations of Igf1r mRNA $(P<0.001)$, IgfBP3 mRNA $(P<0.05)$, IgfBP4 mRNA $(P<0.1)$ and IgfBP6 mRNA $(P<0.05)$. Concentrations of IgfBP5 mRNA were increased in gastrocnemius muscles of $\mathrm{Mstn}^{-1-}$ mice irrespective of the Igf1Ea transgene. Unlike letters denote significance $(P<0.001)$.
\end{abstract}

within individual myofibres until adulthood (White et al. 2010). Given that expression of the Igf1 transgene driven by the MLC promoter is activated after 10 days postpartum (Musaro et al. 2001), the increased production and availability of transgenic IGF1 in postnatal skeletal muscle likely exacerbated the increase in mass of these growing muscles: this booster effect is especially pronounced during the very rapid growth phase in the first 6 weeks after birth (Fig. 3A and B).

IGF1 is required during embryonic and postnatal development (Baker et al. 1993, Liu et al. 1993, Lupu et al. 2001). Locally produced IGF1 (including skeletal muscle), rather than liver derived, is now understood to have the predominant influence on postnatal growth (Sjogren et al. 1999, Yakar et al. 1999). However, there is relatively high expression of both $I g f 1$ and $I g f 2$ mRNA in skeletal muscle during gestation and, for example, in the semitendinosus muscle of pigs, both $I g f 1$ and $I g f 2$ were observed to peak just before parturition and then decline during postnatal life (Lee et al. 1993, Gerrard et al. 1998). Similarly, concentrations of $I g f 1,-2$, and $I g f 1 r$ mRNA are increased in skeletal muscles of rodents after birth and decline in postnatal life by about 1 month in mice (Fiorotto et al. 2014) and 2 months in rats (Adamo et al. 1989, Alexandrides et al. 1989, Shoba et al. 1999). Recently, IGF2 was reported to contribute to the excess muscle

Published by Bioscientifica Ltd. 


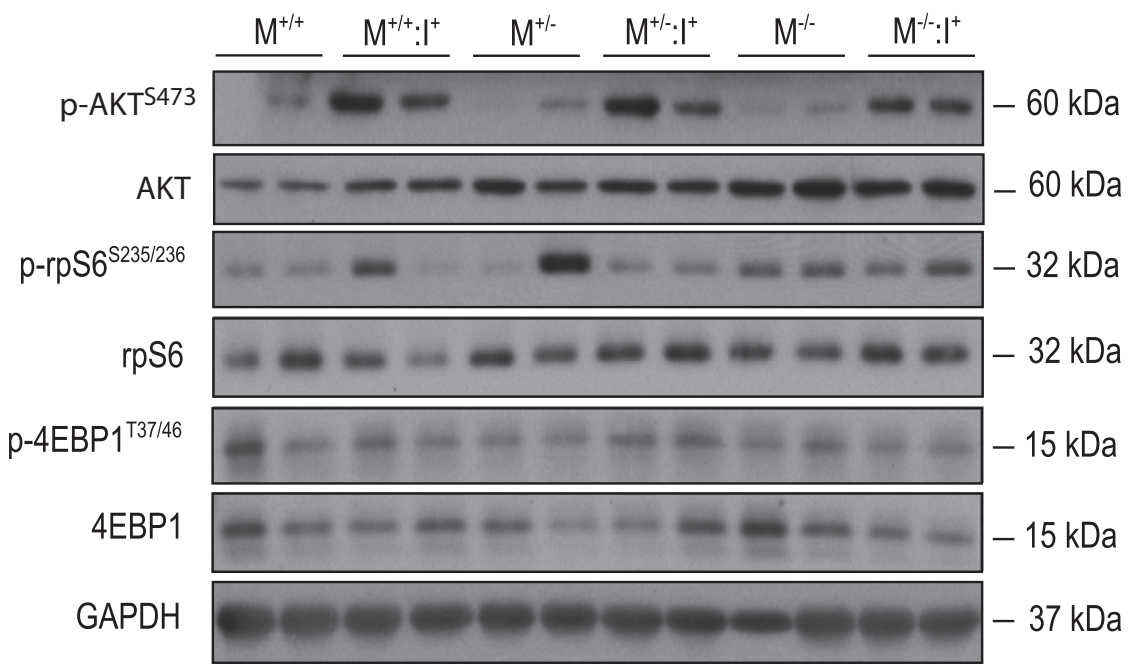

\section{Figure 6}

Representative Western blots of proteins in gastrocnemius muscles from wild-type and transgenic mice (sampled at 12 weeks - Study 2). Representative Western blots of total AKT, phosphorylated (p) AKTs473, total 4EBP1, p4EBP1 ${ }^{137 / 46}$, total rpS6, p-rpS65235/236 and GAPDH in gastrocnemius muscles of $\mathrm{Mstn}^{+/+}\left(\mathrm{M}^{+++}\right)$, Mstn $^{+/-}\left(\mathrm{M}^{+/-}\right)$, Mstn $^{-/-}\left(\mathrm{M}^{-/-}\right)$, Mstn $^{+/+}:$Igf1+ $\left(\mathrm{M}^{+++}: I^{+}\right)$, Mstn $^{+-}:$Igf1+ $\left(\mathrm{M}^{+1-}: \mathrm{I}^{+}\right)$and Mstn $^{-1}: \operatorname{lgf1} 1^{+}\left(\mathrm{M}^{-1-}: \mathrm{I}^{+}\right)$ mice ( $n=8$ per genotype).

development in $\mathrm{Mstn}^{-/-}$mice because concentrations of Igf2 mRNA were higher in muscles of $\mathrm{Mstn}^{-/-}$compared with WT mice postnatally from 3 to 10 weeks of age
(Clark et al. 2015). While the increased concentrations of Igf2 mRNA prevailed in skeletal muscles of $\mathrm{Mstn}^{-/-}$mice, they progressively decline from birth in both $\mathrm{Mstn}^{-1-}$ and
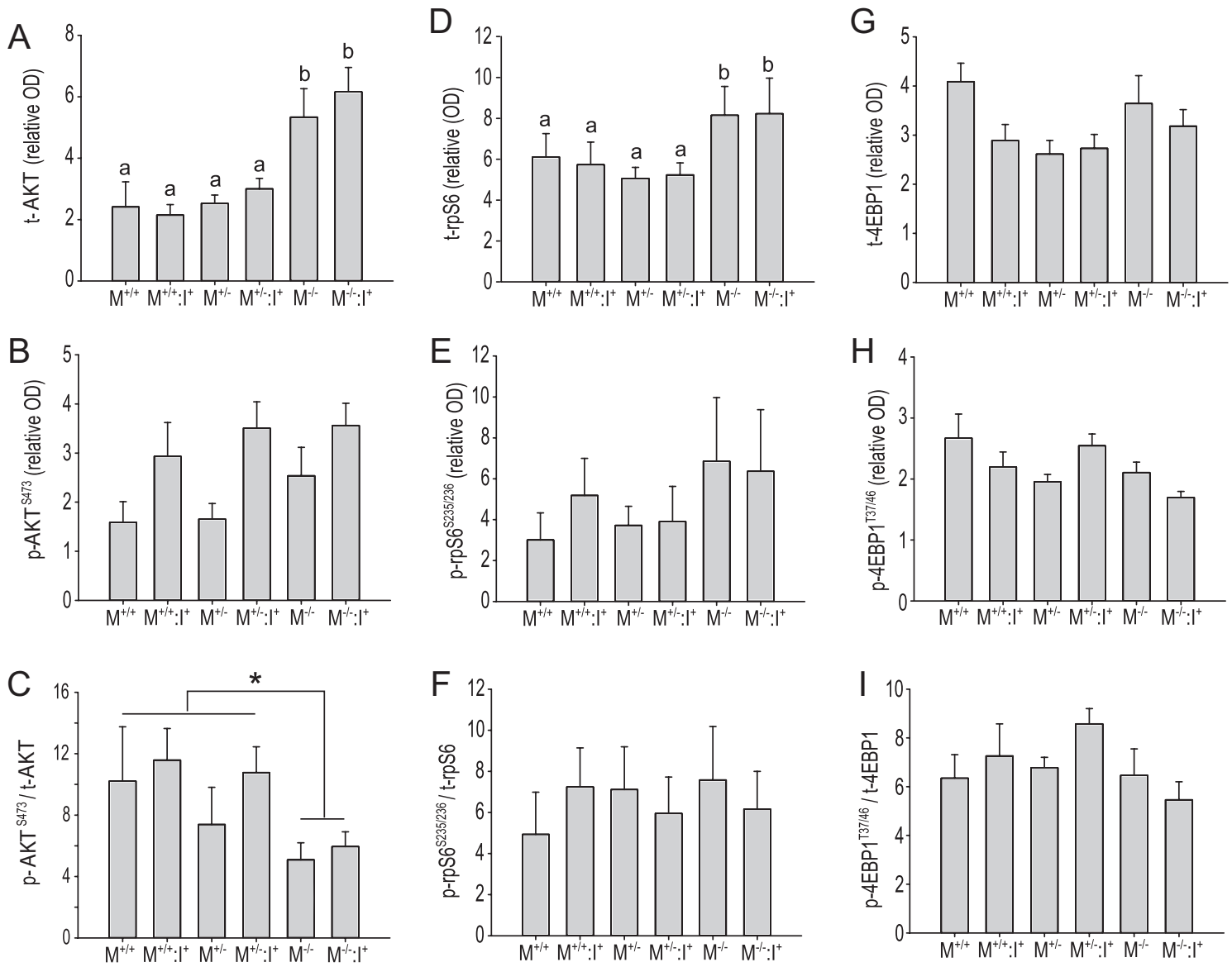

Figure 7

Expression of total and phosphorylated proteins in wild-type and transgenic mice (sampled at 12 weeks - Study 2). Optical density of (A) total (t) Akt, (B) pAKTs473, (C) p-AKTs473/t-AKT, (D) t-rpS6, (E) p-rpS65235/236, (F) p-rpS65235/236/t-rpS6 (G) t-4EBP1, (H) p-4EBP1T37/46, (I) p-4EBP1T37/46/t-4EBP1 in

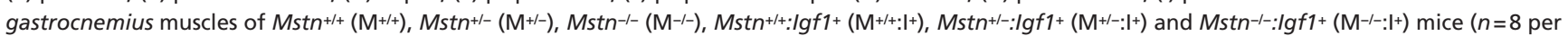
genotype). Unlike letters denote significance $(\mathrm{a}, \mathrm{b} P<0.001)$ and asterisks denote significance where indicated $(* P<0.05)$. 
WT mice (Clark et al. 2015). By contrast, concentrations of Igf1 mRNA were reduced in skeletal muscles of $\mathrm{Mstn}^{-/}$mice up to 3 weeks of age (Clark et al. 2015), and the differences between $\mathrm{Mstn}^{-/-}$and WT were further diminished in mice older than 6 weeks (Kocamis et al. 2002, Clark et al. 2015). The reduced expression of $I g f 1 \mathrm{mRNA}$ in skeletal muscles of juvenile $\mathrm{Mstn}^{-/-}$mice reported here (Study 1) suggested to us that further growth would occur in skeletal muscles if Igf1 expression was increased during postnatal growth.

We observed that the actions of myostatin and IGF1 were quite specific with myostatin regulating hyperplasia and IGF1 regulating hypertrophy, at least in the T. anterior muscle. However, others have shown that the absence of myostatin alone increased both the number and size of myofibres of the EDL, gastrocnemius and T. anterior muscles (McPherron et al. 1997, Amthor et al. 2009). In addition, cultured primary myoblasts from $\mathrm{Mstn}^{-/-}$mice form larger myotubes than those cultured from wild-type mice (Rodriguez et al. 2011), which supports the view that the absence of myostatin permits hypertrophy in vitro. These differences from the current study might be attributable to the different muscles selected and ages of mice that were assessed in other studies ( 2.8 months in our study and 3.2-7 months in the other studies), and may also be explained by differences in the expression of $I g f 1$ and $I g f 1$ receptors, which are crucial for antagonists of TGF- $\beta$ family members to induce hypertrophy (Kalista et al. 2012). In addition, the role of IGF2 in regulating hypertrophy in $\mathrm{Mstn}^{-/-}$mice cannot be overlooked as noted earlier (Clark et al. 2015) and may also explain the increase $(\sim 40 \%)$ in mass of quadriceps muscles in young adult mice when MSTN protein is reduced in skeletal muscles using the Cre/Lox recombinase system to block the expression of Mstn mRNA (Welle et al. 2007). We show that the greatly increased concentrations of IGF1 in the transgenic $I g f 1^{+}$mice enhanced the hypertrophy of skeletal muscle at a younger age, which was particularly evident in Mstn-l- mice.

The reciprocal decline in the mass of the gonadal fat pad with the increased lean mass is consistent with the loss of functional myostatin (Hamrick et al. 2006) and an increase in IGF1 (Fiorotto et al. 2003), which act in conjunction with each other to promote a lean phenotype. Myostatin directs the fate of precursor cells towards a lipogenic lineage (Artaza et al. 2005), while IGF1 promotes a myogenic fate via regulating Rho GTPase (Sordella et al. 2003). Therefore, the combined actions of loss of myostatin and excess IGF1 (in $\mathrm{Mstn}^{-/-}: \mathrm{Igf1}^{+}$) are consistent with promoting the accretion of lean tissue and reduction of fat mass.
We observed that the absence of myostatin together with the presence of transgenic IGF1 altered the myofibre phenotype. These findings accord with those of others who showed that $\mathrm{Mstn}^{-/-}$mice have more myofibres expressing type $2 \mathrm{MyHC}$ in the soleus (type 2A) and EDL muscles (types 2B and 2X) (Girgenrath et al. 2005, Amthor et al. 2007) and that IGF1 directly upregulates the type 2B MyHC promoter (Shanely et al. 2009). Our data accord with the use of the MLC promoter, which is most active in muscles expressing type $2 \mathrm{~B} \mathrm{MyHC}$ and least in the type 1 myofibres (Donoghue et al. 1991, Musaro et al. 2001). The fast and slow twitch characteristics of skeletal muscle are determined by the composition of MyHC and these, in turn, are regulated by the transcriptional co-activator PGC1A, which promotes the development of type 1 myofibres when in excess (Lin et al. 2002) and of type 2B myofibres when absent (Handschin et al. 2007), and that of PGC1B, which promotes the development of type 2X myofibres (Arany et al. 2007). PGC1A acts in conjunction with the myocyte enhancer factor 2c (MEF2c) to promote the development of type 1 myofibres (Potthoff et al. 2007). In support of the switch from slow- to fast-twitch myofibres, the expression of $M e f 2 c$ and Pgc1A mRNA was reduced in skeletal muscles of mice transgenic for IGF1. The tendency for reduced concentrations of $P g c 1 B$ mRNA in skeletal muscles of mice transgenic for IGF1 further supports the switch to type $2 \mathrm{~B}$ myofibres.

We observed that grip strength (at 12 weeks of age) was unaltered among the genotypes when normalised to body mass. This observation is broadly consistent with that of others, who showed that loss of myostatin impaired the generation of force and that skeletal muscles were less resistant to fatigue (Amthor et al. 2007).

In seeking an explanation as to how the two factors co-ordinate the growth of skeletal muscle, we focused on the PI3k/AKT pathway. While IGF1 and myostatin signal primarily via the PI3K/AKT and Smad2/3 pathways, respectively, the former is common to both factors (Trendelenburg et al. 2009, Welle et al. 2009). We show here that the absence of myostatin increases the total abundance of AKT, while additional IGF1 increased its phosphorylation. In addition, we observed an increase in the abundance of total rpS6, but not that of phosphorylated rpS6, or in the ratio of phosphorylated to total rpS6. This contrasts with another report (Welle et al. 2009), wherein a greater abundance of phosphorylated rpS6 was observed, without a change in phosphorylated or total AKT in wild-type mice injected with an antibody to myostatin. The difference between the studies may be explained by the transient effect of an antibody to block myostatin in

Published by Bioscientifica Ltd 
the former study, compared with the constitutive absence of myostatin throughout development in the transgenic mice used here. Furthermore, the lack of difference in total and phosphorylated 4EBP1 in the current study agrees with the observations of others (Welle et al. 2009), but not with our previous study comparing wild-type and $\mathrm{Mstn}^{-/-}$mice where we observed a higher abundance of total 4EBP1 and a lower ratio of phosphorylated to total 4EBP1 (Smith et al. 2014). This observation is not unexpected given that the mice were 12 weeks of age in the current study, an age at which the rate of growth of skeletal muscle was greatly reduced (Fig. 3A) and, therefore, it is understandable that the molecular mechanisms regulating muscle growth would be different. Therefore, we conclude that the greater size of skeletal muscles and reduction in fat in $\mathrm{Mstn}^{-/-}: \mathrm{Igf1}^{+}$ mice can be attributed to the enhanced activation of anabolic signalling via AKT. The increased abundance of rpS6 may help explain the greater rate of protein synthesis in skeletal muscle of $\mathrm{Mstn}^{-/-}$mice (Welle et al. 2006) and hence hypertrophy observed in skeletal muscle of $\mathrm{Mstn}^{-/-}$ mice (McPherron et al. 1997, Amthor et al. 2009).

The lack of increased concentrations of IGF1 in circulation, despite increased concentrations in skeletal muscle, is consistent with an earlier report on the $I g f 1$ (C2:Ea) strain (Shavlakadze et al. 2010). We acknowledge that some transgenic IGF1 may be released into the circulation, but we were unable to differentiate between transgenic and endogenous forms to determine the proportion of transgenic and endogenous IGF1 in circulation. In addition, specific binding proteins are known to bind to and regulate the bioavailability of IGF1 (Clemmons 1998). We anticipated that expression of the binding proteins in skeletal muscle would be increased to potentially (1) reduce the anabolic actions of IGF1 because the expression of IGF1 receptors was reduced in skeletal muscle and (2) retain IGF1 in the muscle bed to prevent it from entering circulation. However, we observed reduced concentrations of binding proteins 3, 4 and 6 mRNA in muscles transgenic for IGF1. The exception was the expression of Igfbp5 mRNA, which was increased in skeletal muscles of $\mathrm{Mstn}^{-1-}$ mice. Others have also reported higher expression of $I g f b p 5$ mRNA in skeletal muscles of $\mathrm{Mstn}^{-/-}$mice (Clark et al. 2015). While the role of IGFBP5 is unclear, overexpression reduced birth weight and retarded the development of skeletal muscles (Salih et al. 2004). Therefore, it is likely that increased Igfbp5 mRNA in skeletal muscles of $\mathrm{Mstn}^{-/-}$mice (both control and $\mathrm{Ig} f \mathrm{I}^{+}$) may be acting to limit the excess growth of skeletal muscle induced by the absence of myostatin.
We conclude that myostatin regulates myofibre number, while IGF1 regulates myofibre size, at least in the T. anterior muscle, and that both conditions (Mstn-l- and $I g f 1^{+}$) increase the proportion of fast $2 \mathrm{~B}$ myofibres in hind limb muscles of young adult male mice. The combination of an increase in myofibre number and size is greater than the additive effects of these genes alone on muscle mass, which culminates in an extremely lean phenotype.

Declaration of interest

The authors declare that there is no conflict of interest that could be perceived as prejudicing the impartiality of the research reported.

\section{Funding}

The authors gratefully acknowledge funding from the Foundation of Research, Science and Technology (New Enterprise Research Fund C10X0703), New Zealand.

\section{Author contribution statement}

A H, C D M, F J, H K S, M D G, PS, TS, M L F interpreted the data and wrote the manuscript. A H, J O, S F, C B, G N, J B, P S and M S S collected and analysed the data. CD M, K M and T W conducted the animal experiments.

\section{Acknowledgements}

The authors are grateful to Ric Broadhurst, Bobby Smith and Genevieve Sheriff for looking after mice in the Small Animal Colony at Ruakura and to Dr Harold Henderson from AgResearch Ltd for advice with statistics.

\section{References}

Adamo M, Lowe WL Jr, LeRoith D \& Roberts CT Jr 1989 Insulinlike growth factor I messenger ribonucleic acids with alternative 5 '-untranslated regions are differentially expressed during development of the rat. Endocrinology 124 2737-2744. (doi:10.1210/ endo-124-6-2737)

Alexandrides T, Moses AC \& Smith RJ 1989 Developmental expression of receptors for insulin, insulin-like growth factor I (IGF-I), and IGF-II in rat skeletal muscle. Endocrinology 124 1064-1076. (doi:10.1210/endo124-2-1064)

Amthor H, Nicholas G, McKinnell I, Kemp CF, Sharma M, Kambadur R \& Patel K 2004 Follistatin complexes myostatin and antagonises myostatin-mediated inhibition of myogenesis. Developmental Biology 270 19-30. (doi:10.1016/j.ydbio.2004.01.046)

Amthor H, Macharia R, Navarrete R, Schuelke M, Brown SC, Otto A, Voi T, Muntoni F, Vrbova G, Partridge T, et al. 2007 Lack of myostatin results in excessive muscle growth but impaired force generation. PNAS 104 1835-1840. (doi:10.1073/pnas.0604893104)

Amthor H, Otto A, Vulin A, Rochat A, Dumonceaux J, Garcia L, Mouisel E, Hourde C, Macharia R, Friedrichs M, et al. 2009 Muscle hypertrophy driven by myostatin blockade does not require stem/precursor-cell activity. PNAS 106 7479-7484. (doi:10.1073/ pnas.0811129106)

Published by Bioscientifica Ltd. 
Arany Z, Lebrasseur N, Morris C, Smith E, Yang W, Ma Y, Chin S \& Spiegelman BM 2007 The transcriptional coactivator PGC-1beta drives the formation of oxidative type IIX fibers in skeletal muscle. Cell Metabolism 5 35-46. (doi:10.1016/j.cmet.2006.12.003)

Artaza JN, Bhasin S, Magee TR, Reisz-Porszasz S, Shen R, Groome NP, Fareez MM \& Gonzalez-Cadavid NF 2005 Myostatin inhibits myogenesis and promotes adipogenesis in C3H 10T(1/2) mesenchymal multipotent cells. Endocrinology 146 3547-3557. (doi:10.1210/en.2005-0362)

Augusto V, Padovani CR \& Campos GER 2004 Skeletal muscle fiber types in C57BL6J mice. Brazilian Journal of Morphological Sciences 21 89-94.

Baker J, Liu JP, Robertson EJ \& Efstratiadis A 1993 Role of insulin-like growth factors in embryonic and postnatal growth. Cell 75 73-82. (doi:10.1016/S0092-8674(05)80085-6)

Barton-Davis ER, Shoturma DI, Musaro A, Rosenthal N \& Sweeney HL 1998 Viral mediated expression of insulin-like growth factor I blocks the aging-related loss of skeletal muscle function. PNAS $\mathbf{9 5}$ 15603-15607. (doi:10.1073/pnas.95.26.15603)

Blough ER, Rennie ER, Zhang F \& Reiser PJ 1996 Enhanced electrophoretic separation and resolution of myosin heavy chains in mammalian and avian skeletal muscles. Analytical Biochemistry 233 31-35. (doi:10.1006/abio.1996.0003)

Briguet A, Courdier-Fruh I, Foster M, Meier T \& Magyar JP 2004 Histological parameters for the quantitative assessment of muscular dystrophy in the mdx-mouse. Neuromuscular Disorders 14 675-682. (doi:10.1016/j.nmd.2004.06.008)

Clark DL, Clark DI, Hogan EK, Kroscher KA \& Dilger AC 2015 Elevated insulin-like growth factor 2 expression may contribute to the hypermuscular phenotype of myostatin null mice. Growth Hormone and IGF Research 25 207-218. (doi:10.1016/j.ghir.2015.06.007)

Clemmons DR 1998 Role of insulin-like growth factor binding proteins in controlling IGF actions. Molecular and Cellular Endocrinology 140 19-24. (doi:10.1016/S0303-7207(98)00024-0)

Dever TE 2002 Gene-specific regulation by general translation factors. Cell 108 545-556. (doi:10.1016/S0092-8674(02)00642-6)

Donoghue MJ, Alvarez JD, Merlie JP \& Sanes JR 1991 Fiber type- and position-dependent expression of a myosin light chain-CAT transgene detected with a novel histochemical stain for CAT. Journal of Cell Biology 115 423-434. (doi:10.1083/jcb.115.2.423)

Fiorotto ML, Davis TA, Sosa HA, Villegas-Montoya C, Estrada I \& Fleischmann R 2014 Ribosome abundance regulates the recovery of skeletal muscle protein mass upon recuperation from postnatal undernutrition in mice. Journal of Physiology 592 5269-5286. (doi:10.1113/jphysiol.2014.279067)

Fiorotto ML, Schwartz RJ \& Delaughter MC 2003 Persistent IGF-I overexpression in skeletal muscle transiently enhances DNA accretion and growth. FASEB Journal 17 59-60. (doi:10.1096/fj.02-0289fje)

Gao CQ, Zhi R, Yang Z, Li HC, Yan HC \& Wang XQ 2015 Low dose of IGF-I increases cell size of skeletal muscle satellite cells via Akt/S6K signaling pathway. Journal of Cellular Biochemistry 116 2637-2648. (doi:10.1002/jcb.25212)

GenStat 2003 Lawes Agricultural Trust (Rothamsted Experimental Station). London, UK: VSN International Ltd.

Gerrard DE, Okamura CS, Ranalletta MA \& Grant AL 1998 Developmental expression and location of IGF-I and IGF-II mRNA and protein in skeletal muscle. Journal of Animal Science 76 1004-1011. (doi:10.2527/1998.7641004x)

Girgenrath S, Song K \& Whittemore LA 2005 Loss of myostatin expression alters fiber-type distribution and expression of myosin heavy chain isoforms in slow- and fast-type skeletal muscle. Muscle and Nerve 31 34-40. (doi:10.1002/mus.20175)

Hamalainen N \& Pette D 1993 The histochemical profiles of fast fiber types IIB, IID, and IIA in skeletal muscles of mouse, rat, and rabbit. Journal of Histochemistry and Cytochemistry 41 733-743. (doi:10.1177/41.5.8468455)
Hamrick MW, Pennington C, Webb CN \& Isales CM 2006 Resistance to body fat gain in 'double-muscled' mice fed a high-fat diet. International Journal of Obesity 30 868-870. (doi:10.1038/ sj.ijo.0803200)

Handschin C, Chin S, Li P, Liu F, Maratos-Flier E, Lebrasseur NK, Yan Z \& Spiegelman BM 2007 Skeletal muscle fiber-type switching, exercise intolerance, and myopathy in PGC-1alpha muscle-specific knock-out animals. Journal of Biological Chemistry $28230014-30021$. (doi:10.1074/jbc.M704817200)

Kalista S, Schakman O, Gilson H, Lause P, Demeulder B, Bertrand L, Pende M \& Thissen JP 2012 The type 1 insulin-like growth factor receptor (IGF-IR) pathway is mandatory for the follistatin-induced skeletal muscle hypertrophy. Endocrinology 153 241-253. (doi:10.1210/en.2011-1687)

Kocamis H, Gahr SA, Batelli L, Hubbs AF \& Killefer J 2002 IGF-I, IGF-II, and IGF-receptor-1 transcript and IGF-II protein expression in myostatin knockout mice tissues. Muscle and Nerve 26 55-63. (doi:10.1002/mus.10160)

Laplante M \& Sabatini DM 2012 mTOR signaling in growth control and disease. Cell 149 274-293. (doi:10.1016/j.cell.2012.03.017)

Latres E, Pangilinan J, Miloscio L, Bauerlein R, Na E, Potocky TB, Huang Y, Eckersdorff M, Rafique A, Mastaitis J, et al. 2015 Myostatin blockade with a fully human monoclonal antibody induces muscle hypertrophy and reverses muscle atrophy in young and aged mice. Skelet Muscle 5 34. (doi:10.1186/s13395-015-0060-8)

Lee SJ \& McPherron AC 2001 Regulation of myostatin activity and muscle growth. PNAS 98 9306-9311. (doi:10.1073/pnas.151270098)

Lee CY, Chung CS \& Simmen FA 1993 Ontogeny of the porcine insulinlike growth factor system. Molecular and Cellular Endocrinology 93 71-80. (doi:10.1016/0303-7207(93)90141-6)

Li M, Zhou X, Chen Y, Nie Y, Huang H, Chen H \& Mo D 2015 Not all the number of skeletal muscle fibers is determined prenatally. BMC Developmental Biology 15 42. (doi:10.1186/s12861-015-0091-8)

Lin J, Wu H, Tarr PT, Zhang CY, Wu Z, Boss O, Michael LF, Puigserver P, Isotani E, Olson EN, et al. 2002 Transcriptional co-activator PGC-1 alpha drives the formation of slow-twitch muscle fibres. Nature $\mathbf{4 1 8}$ 797-801. (doi:10.1038/nature00904)

Liu JP, Baker J, Perkins AS, Robertson EJ \& Efstratiadis A 1993 Mice carrying null mutations of the genes encoding insulin-like growth factor I (Igf-1) and type 1 IGF receptor (Igf1r). Cell 75 59-72. (doi:10.1016/s0092-8674(05)80084-4)

Lundby C, Nordsborg N, Kusuhara K, Kristensen KM, Neufer PD \& Pilegaard H 2005 Gene expression in human skeletal muscle: alternative normalization method and effect of repeated biopsies. European Journal of Applied Physiology 95 351-360. (doi:10.1007/ s00421-005-0022-7)

Lupu F, Terwilliger JD, Lee K, Segre GV \& Efstratiadis A 2001 Roles of growth hormone and insulin-like growth factor 1 in mouse postnatal growth. Developmental Biology 229 141-162. (doi:10.1006/ dbio.2000.9975)

Magnuson B, Ekim B \& Fingar DC 2012 Regulation and function of ribosomal protein S6 kinase (S6K) within mTOR signalling networks. Biochemistry Journal 441 1-21. (doi:10.1042/BJ20110892)

McMahon CD, Chai R, Radley-Crabb HG, Watson T, Matthews KG, Sheard PW, Soffe Z, Grounds MD \& Shavlakadze T 2014 Lifelong exercise and locally produced insulin-like growth factor-1 (IGF-1) have a modest influence on reducing age-related muscle wasting in mice. Scandinavian Journal of Medicine and Science in Sports 24 e423-e435. (doi:10.1111/sms.12200)

McPherron AC, Lawler AM \& Lee SJ 1997 Regulation of skeletal muscle mass in mice by a new TGF-beta superfamily member. Nature $\mathbf{3 8 7}$ 83-90. (doi:10.1038/387083a0)

Morissette MR, Cook SA, Buranasombati C, Rosenberg MA \& Rosenzweig A 2009 Myostatin inhibits IGF-I-induced myotube hypertrophy through Akt. American Journal of Physiology: Cell Physiology 297 C1124-C1132. (doi:10.1152/ajpcell.00043.2009) http://joe.endocrinology-journals.org

DOI: $10.1530 / J O E-17-0032$
(C) 2017 Society for Endocrinology Printed in Great Britain 
Morita M, Gravel SP, Hulea L, Larsson O, Pollak M, St-Pierre J \& Topisirovic I 2015 mTOR coordinates protein synthesis, mitochondrial activity and proliferation. Cell Cycle 14 473-480. (doi:1 $0.4161 / 15384101.2014 .991572$ )

Musaro A, McCullagh K, Paul A, Houghton L, Dobrowolny G, Molinaro M, Barton ER, Sweeney HL \& Rosenthal N 2001 Localized Igf-1 transgene expression sustains hypertrophy and regeneration in senescent skeletal muscle. Nature Genetics 27 195-200. (doi:10.1038/84839)

Ontell M, Feng KC, Klueber K, Dunn RF \& Taylor F 1984 Myosatellite cells, growth, and regeneration in murine dystrophic muscle: a quantitative study. Anatomical Record 208 159-174. (doi:10.1002/ ar.1092080203)

Potthoff MJ, Wu H, Arnold MA, Shelton JM, Backs J, McAnally J, Richardson JA, Bassel-Duby R \& Olson EN 2007 Histone deacetylase degradation and MEF2 activation promote the formation of slowtwitch myofibers. Journal of Clinical Investigation $1172459-2467$. (doi:10.1172/JCI31960)

Proud CG 2004 mTOR-mediated regulation of translation factors by amino acids. Biochemical and Biophysical Research Communications $\mathbf{3 1 3}$ 429-436. (doi:10.1016/j.bbrc.2003.07.015)

Rebbapragada A, Benchabane H, Wrana JL, Celeste AJ \& Attisano L 2003 Myostatin signals through a transforming growth factor beta-like signaling pathway to block adipogenesis. Molecular and Cellular Biology 23 7230-7242. (doi:10.1128/MCB.23.20.7230-7242.2003)

Retamales A, Zuloaga R, Valenzuela CA, Gallardo-Escarate C, Molina A \& Valdes JA 2015 Insulin-like growth factor-1 suppresses the myostatin signaling pathway during myogenic differentiation. Biochemical and Biophysical Research Communications 464 596-602. (doi:10.1016/j. bbrc.2015.07.018)

Rodriguez J, Vernus B, Toubiana M, Jublanc E, Tintignac L, Leibovitch S \& Bonnieu A 2011 Myostatin inactivation increases myotube size through regulation of translational initiation machinery. Journal of Cellular Biochemistry 112 3531-3542. (doi:10.1002/jcb.23280)

Rogers P \& Webb GP 1980 Estimation of body fat in normal and obese mice. British Journal of Nutrition 43 83-86. (doi:10.1079/BJN19800066)

Rommel C, Bodine SC, Clarke BA, Rossman R, Nunez L, Stitt TN, Yancopoulos GD \& Glass DJ 2001 Mediation of IGF-1-induced skeletal myotube hypertrophy by PI(3)K/Akt/mTOR and PI(3)K/Akt/GSK3 pathways. Nature Cell Biology 3 1009-1013. (doi:10.1038/ncb1101-1009)

Rosenthal N, Kornhauser JM, Donoghue M, Rosen KM \& Merlie JP 1989 Myosin light chain enhancer activates muscle-specific, developmentally regulated gene expression in transgenic mice. PNAS 86 7780-7784. (doi:10.1073/pnas.86.20.7780)

Rowe RW \& Goldspink G 1969 Muscle fibre growth in five different muscles in both sexes of mice. Journal of Anatomy 104 519-530.

Ruvinsky I \& Meyuhas O 2006 Ribosomal protein S6 phosphorylation: from protein synthesis to cell size. Trends in Biochemical Sciences $\mathbf{3 1}$ 342-348. (doi:10.1016/j.tibs.2006.04.003)

Salih DA, Tripathi G, Holding C, Szestak TA, Gonzalez MI, Carter EJ, Cobb LJ, Eisemann JE \& Pell JM 2004 Insulin-like growth factor-binding protein 5 (Igfbp5) compromises survival, growth, muscle development, and fertility in mice. PNAS $1014314-4319$. (doi:10.1073/pnas.0400230101)

Shanely RA, Zwetsloot KA, Childs TE, Lees SJ, Tsika RW \& Booth FW 2009 IGF-I activates the mouse type IIb myosin heavy chain gene. American Journal of Physiology: Cell Physiology 297 C1019-C1027. (doi:10.1152/ ajpcell.00169.2009)

Shavlakadze T, Winn N, Rosenthal N \& Grounds MD 2005 Reconciling data from transgenic mice that overexpress IGF-I specifically in skeletal muscle. Growth Hormone and IGF Research 15 4-18. (doi:10.1016/j.ghir.2004.11.001)
Shavlakadze T, Chai J, Maley K, Cozens G, Grounds G, Winn N, Rosenthal N \& Grounds MD 2010 A growth stimulus is needed for IGF-1 to induce skeletal muscle hypertrophy in vivo. Journal of Cell Science 123 960-971. (doi:10.1242/jcs.061119)

Shen WH, Boyle DW, Wisniowski P, Bade A \& Liechty EA 2005 Insulin and IGF-I stimulate the formation of the eukaryotic initiation factor $4 \mathrm{~F}$ complex and protein synthesis in C2C12 myotubes independent of availability of external amino acids. Journal of Endocrinology 185 275-289. (doi:10.1677/joe.1.06080)

Shoba L, An MR, Frank SJ \& Lowe WL Jr 1999 Developmental regulation of insulin-like growth factor-I and growth hormone receptor gene expression. Molecular and Cellular Endocrinology 152 125-136. (doi:10.1016/S0303-7207(99)00045-3)

Sjogren K, Liu JL, Blad K, Skrtic S, Vidal O, Wallenius V, LeRoith D, Tornell J, Isaksson OG, Jansson JO, et al. 1999 Liver-derived insulinlike growth factor I (IGF-I) is the principal source of IGF-I in blood but is not required for postnatal body growth in mice. PNAS 96 7088-7092. (doi:10.1073/pnas.96.12.7088)

Smith HK, Matthews KG, Oldham JM, Jeanplong F, Falconer SJ, Bass JJ, Senna-Salerno M, Bracegirdle JW \& McMahon CD 2014 Translational signalling, atrogenic and myogenic gene expression during unloading and reloading of skeletal muscle in myostatin-deficient mice. PLoS ONE 9 e94356. (doi:10.1371/journal.pone.0094356)

Sordella R, Jiang W, Chen GC, Curto M \& Settleman J 2003 Modulation of Rho GTPase signaling regulates a switch between adipogenesis and myogenesis. Cell 113 147-158. (doi:10.1016/S0092-8674(03)00271-X)

Timson BF \& Dudenhoeffer GA 1990 Skeletal muscle fibre number in the rat from youth to adulthood. Journal of Anatomy 173 33-36.

Trendelenburg AU, Meyer A, Rohner D, Boyle J, Hatakeyama S \& Glass DJ 2009 Myostatin reduces Akt/TORC1/p70S6K signaling, inhibiting myoblast differentiation and myotube size. American Journal of Physiology: Cell Physiology 296 C1258-C1270. (doi:10.1152/ ajpcell.00105.2009)

Welle S, Bhatt K \& Pinkert CA 2006 Myofibrillar protein synthesis in myostatin-deficient mice. American Journal of Physiology: Endocrinology and Metabolism 290 E409-E415. (doi:10.1152/ajpendo.00433.2005)

Welle S, Bhatt K, Pinkert CA, Tawil R \& Thornton CA 2007 Muscle growth after postdevelopmental myostatin gene knockout. American Journal of Physiology: Endocrinology and Metabolism 292 E985-E991. (doi:10.1152/ajpendo.00531.2006)

Welle S, Burgess K \& Mehta S 2009 Stimulation of skeletal muscle myofibrillar protein synthesis, p70 S6 kinase phosphorylation, and ribosomal protein S6 phosphorylation by inhibition of myostatin in mature mice. American Journal of Physiology: Endocrinology and Metabolism 296 E567-E572. (doi:10.1152/ajpcell.00154.2009)

White RB, Bierinx AS, Gnocchi VF \& Zammit PS 2010 Dynamics of muscle fibre growth during postnatal mouse development. BMC Developmental Biology 1021 . (doi:10.1186/1471-213X-10-21)

White Z, Terrill J, White RB, McMahon C, Sheard P, Grounds MD \& Shavlakadze T 2016 Voluntary resistance wheel exercise from mid-life prevents sarcopenia and increases markers of mitochondrial function and autophagy in muscles of old male and female C57BL/6J mice. Skelet Muscle 6 45. (doi:10.1186/s13395-016-0117-3)

Winbanks CE, Weeks KL, Thomson RE, Sepulveda PV, Beyer C, Qian H, Chen JL, Allen JM, Lancaster GI, Febbraio MA, et al. 2012 Follistatinmediated skeletal muscle hypertrophy is regulated by Smad3 and mTOR independently of myostatin. Journal of Cell Biology 197 997-1008. (doi:10.1083/jcb.201109091)

Yakar S, Liu JL, Stannard B, Butler A, Accili D, Sauer B \& LeRoith D 1999 Normal growth and development in the absence of hepatic insulin-like growth factor I. PNAS 96 7324-7329. (doi:10.1073/ pnas.96.13.7324)

Received in final form 23 April 2017

Accepted 22 May 2017

Accepted Preprint published online 22 May 2017 http://joe.endocrinology-journals.org

DOI: 10.1530/JOE-17-0032
(C) 2017 Society for Endocrinology Printed in Great Britain 